\title{
Noradrenaline transporter blockade increases fronto- parietal functional connectivity relevant for working memory
}

Citation for published version (APA):

Hernaus, D., Marta, M., Santa, C., Offermann, J. S., \& Van Amelsvoort, T. (2017). Noradrenaline transporter blockade increases fronto-parietal functional connectivity relevant for working memory. European Neuropsychopharmacology, 27(4), 399-410. https://doi.org/10.1016/j.euroneuro.2017.02.004

Document status and date:

Published: 01/04/2017

DOI:

10.1016/j.euroneuro.2017.02.004

Document Version:

Publisher's PDF, also known as Version of record

\section{Document license:}

Taverne

\section{Please check the document version of this publication:}

- A submitted manuscript is the version of the article upon submission and before peer-review. There can be important differences between the submitted version and the official published version of record.

People interested in the research are advised to contact the author for the final version of the publication, or visit the DOI to the publisher's website.

- The final author version and the galley proof are versions of the publication after peer review.

- The final published version features the final layout of the paper including the volume, issue and page numbers.

Link to publication

\footnotetext{
General rights rights.

- You may freely distribute the URL identifying the publication in the public portal. please follow below link for the End User Agreement:

www.umlib.nl/taverne-license

Take down policy

If you believe that this document breaches copyright please contact us at:

repository@maastrichtuniversity.nl

providing details and we will investigate your claim.
}

Copyright and moral rights for the publications made accessible in the public portal are retained by the authors and/or other copyright owners and it is a condition of accessing publications that users recognise and abide by the legal requirements associated with these

- Users may download and print one copy of any publication from the public portal for the purpose of private study or research.

- You may not further distribute the material or use it for any profit-making activity or commercial gain

If the publication is distributed under the terms of Article $25 \mathrm{fa}$ of the Dutch Copyright Act, indicated by the "Taverne" license above, 


\title{
Noradrenaline transporter blockade increases fronto-parietal functional connectivity relevant for working memory
}

\author{
Dennis Hernaus ${ }^{\mathrm{a}, *}$, Marta $\mathrm{M}^{\mathrm{a}}$ Casales Santa ${ }^{\mathrm{b}}$, \\ Jan Stefan Offermann ${ }^{\mathrm{b}}$, Thérèse Van Amelsvoort ${ }^{\mathrm{b}}$
}

\author{
a University of Maryland School of Medicine, Department of Psychiatry; Maryland Psychiatric Research \\ Center, MD, USA \\ ${ }^{\mathrm{b}}$ Department of Psychiatry and Neuropsychology, South Limburg Mental Health Research and Teaching \\ Network, EURON, School for Mental Health and NeuroScience MHeNS Maastricht University, Maastricht, \\ The Netherlands
}

Received 31 October 2016; received in revised form 20 January 2017; accepted 21 February 2017

\author{
KEYWORDS \\ FMRI; \\ Prefrontal cortex; \\ Dopamine; \\ Noradrenaline; \\ Working memory; \\ Cognition
}

\begin{abstract}
Experimental animal work has demonstrated that dopamine and noradrenaline play an essential role in modulating prefrontal cortex-mediated networks underlying working memory performance. Studies of functional connectivity have been instrumental in extending such notions to humans but, so far, have almost exclusively focussed on pharmacological agents with a predominant dopaminergic mechanism of action. Here, we investigate the effect of a single dose of atomoxetine $60 \mathrm{mg}$, a noradrenaline transporter inhibitor, on working memory performance and associated functional connectivity during an n-back task in 19 healthy male volunteers. Atomoxetine increased functional connectivity between right anterior insula and dorsolateral prefrontal cortex, precentral gyrus, posterior parietal cortex and precuneus during the high-working memory load condition of the n-back task. Increased atomoxetine-induced insula-dorsolateral prefrontal cortex functional connectivity during this condition correlated with decreased reaction time variability and was furthermore predicted by working memory capacity. These results show for the first time that noradrenaline transporter blockade-induced increases in cortical catecholamines accentuate fronto-parietal working memory-related network integrity. The observation of significant inter-subject variability in response to atomoxetine has implications for inverted-U frameworks of dopamine and noradrenaline function, which could be useful to predict drug effects in clinical disorders with variable treatment response.
\end{abstract}

(c) 2017 Elsevier B.V. and ECNP. All rights reserved.

*Correspondence to: Department of Psychiatry; Maryland Psychiatric Research Center, P.O. Box 21247, Baltimore, MD 21228 USA.

E-mail address: dhernaus@mprc.umaryland.edu (D. Hernaus). 


\section{Introduction}

Cortical dopamine (DA) and noradrenaline (NA) play an essential role in orchestrating neural networks underlying working memory and attention (Goldman-Rakic, 1995). While a wide range of brain networks underlie these executive functions, they most consistently depend on contributions from prefrontal cortex (PFC)-mediated networks that among others include dorsolateral prefrontal cortex (dIPFC), anterior cingulate cortex and insula (Niendam et al., 2012). A better understanding of DA and NA's action in PFC-mediated networks could improve pharmacological treatment of mental disorders associated with cognitive deficits such as schizophrenia (Glahn et al., 2005; Zhang et al., 2016) and attention-deficit hyperactivity disorder (Hart et al., 2013) (ADHD). Here, we investigate for the first time how NA transporter blockade modulates frontal cortical functional connectivity (FC) in healthy volunteers during a working memory paradigm, how this relates to task performance and how inter-individual differences predict these effects.

The ability of catecholamines to sculpt neuronal networks is directly related to their signal-to-noise modulating properties: DA receptor subtype 1 (D1) activation selectively decreases resource allocation to 'noise' processing (Arnsten, 2011; Vijayraghavan et al., 2007), thought to facilitate a state of focused attention (Seamans et al., 2001). In contrast, D1 blockade markedly decreases delayed working memory performance (Sawaguchi and Goldman-Rakic, 1994) and D2 stimulation increases activity in response-related networks thought to underlie a more flexible form of attention (Arnsten, 2011). Modulation of $\gamma$-aminobutyric acid (GABA)ergic interneuron excitability is one essential mechanism by which DA tunes PFC-mediated neural networks (Seamans et al., 2001), with these GABAergic interneurons projecting onto pyramidal neurons. In comparison, NA optimizes PFC-mediated networks by increasing 'signal' processing, rather than decreasing noise (Arnsten, 2011); stimulation of $\alpha 2 \mathrm{~A}$-adrenoceptors increases activity of neural ensembles that fire for similar preferred directions during a spatial working memory task. In contrast, pharmacological blockade of these receptors impairs working memory performance and decreases overall PFC functionality (Wang et al., 2007). Correspondingly, pharmacological agents that increase extracellular cortical DA and NA have been shown to increase signal and decrease noise-related firing of neurons (Gamo et al., 2010).

While the notion that catecholamines are essential regulators of PFC-mediated networks has been extensively validated in experimental animals, evidence in humans stems from indirect sources. Studies of FC - a neuroimaging technique that assesses task-dependent correlations between brain areas (O'Reilly et al., 2012) - have played an important role in unraveling how catecholaminergic activity reorganizes functional brain networks in man. However, the majority of these studies have focused on the DA system. For example, D2 agonism
(Bloemendaal et al., 2015) and D1 antagonism (Rieckmann et al., 2012) modulate FC of working memory networks involving dIPFC, a region essential for working memory performance and part of a taskpositive network (Niendam et al., 2012). Moreover, levodopa, which increases extracellular DA over and above NA (Dolphin et al., 1976; Everett and Borcherding, 1970), and D2 antagonist haloperidol exert opposing effects on frontal cortico-striatal FC at rest (Cole et al., 2013).

How selective NA transporter blockade affects the integrity of functional brain networks that subserve executive functions is less clear. In Parkinson's disease, atomoxetine a potent NA transporter inhibitor that increases extracellular cortical DA and NA (Bymaster et al., 2002) - increases resting-state FC between dIPFC and anterior cingulate cortex, which correlates with a measure of drug-induced cognitive improvement (Borchert et al., 2016). Moreover, atomoxetine weakens FC within the default-mode network (van den Brink et al., 2016), a task-negative network in which activity decreases with increasing task demands (i.e. task-related deactivation). In the current study, we investigated how a single dose of atomoxetine impacted FC of PFC regions during a well-validated working memory task. We predicted that NA transporter blockade, similar to studies of DA agonism, would I) preferentially accentuate FC between PFC regions relevant for task performance, and, II) that drug-induced changes in FC correlated with task performance parameters sensitive to changes in catecholamine function.

Importantly, however, considerable variation exists in the effect of catecholamine-enhancing agents on cognition-related brain activity and cognitive performance, which can be predicted by surrogate markers of catecholamine function such as catechol-o-methyl transferase (COMT) genotype (Mattay et al., 2003) (although also see (Wardle et al., 2013)) and baseline working memory capacity (Kimberg et al., 1997; Mehta et al., 2004). We therefore additionally hypothesized that the extent to which atomoxetine modulated FC within taskrelevant PFC regions is dependent on baseline catecholamine function. To these aims, we obtained a measure of working memory capacity which has previously shown to predict the effect of methylphenidate on working memory-related brain function (Mehta et al., 2000), cognitive performance (Mehta et al., 2004) and DA synthesis capacity (Cools et al., 2008). In accordance with previous work (Cools et al., 2008; Kimberg et al., 1997; Mehta et al., 2004), we hypothesized that individuals with the lowest working memory capacity would show the greatest increase in task-positive PFC FC following atomoxetine administration.

\section{Experimental procedures}

\subsection{Participants}

Twenty-two healthy male right-handed non-smokers between 18-30 years were recruited from a student population $(M=23.26$, 
$\mathrm{SD}=2.64$ ) using pamphlets and online advertising. Exclusion criteria were: diagnosis of a psychiatric or neurological disorder, psychopharmacological treatment (past/present), high $(>30)$ or low $(<18)$ BMI, current recreational drug (ab)use, and magnetic resonance imaging (MRI) contraindications. During each study session, a urine sample was screened for the presence of amphetamine, tetrahydrocannabinol, cocaine, opiates, methamphetamine and benzodiazepines. Two participants were excluded from the experiment due to current recreational drug use; one other participant did not finish the experiment due to emesis following atomoxetine (from here on: ATX) administration. The final sample thus consisted of nineteen participants. The study was carried out in accordance with the Declaration of Helsinki and was approved by the local medical ethics committee of Maastricht University Medical Centre (NL53913.068.15). All participants gave written informed consent prior to each session and were reimbursed for participation.

\subsection{Study procedures}

We employed a double-blind randomized placebo (PLC)-controlled crossover design (PLC-ATX $n=8$; ATX-PLC $n=11$ ). All participants received an oral dose of ATX (Strattera $\left.{ }^{\mathbb{R}}\right)$ and cellulose microcrystal (PLC) in capsule form between 12 and $4 \mathrm{pm}$ on two separate days, separated in time by a minimum of one week. To increase comparability to previous work (Hester et al., 2012; Lissek et al., 2015; Marquand et al., 2012) and approximate clinically efficacious dosing (Gilbert et al., 2006), a single dose of ATX $60 \mathrm{mg}$ was selected. At clinical doses, ATX occupies $>90 \%$ of the NAT in nonhuman primates (Ding et al., 2014). Our choice for ATX was motivated by the observation that, at single doses, ATX increases extracellular DA and NA in PFC, but not striatal, regions (Bymaster et al., 2002).

All participants abstained from caffeine and alcohol on the day of a session. At the start of the first session, participants were trained on the n-back task until they exceeded $85 \%$ correct responses in every condition. In light of FC's sensitivity to motion (Power et al., 2012), participants underwent a mock scanning session on both occasions, during which they were trained at a threshold of $<.5 \mathrm{~mm}$ to exert minimal movement. In line with previous work (Cubillo et al., 2014; Marquand et al., 2012) and the pharmacokinetics of ATX (Witcher et al., 2003), participants performed the n-back at $100 \mathrm{~min}( \pm 10)$ after capsule intake. Except for one participant that experienced nausea (excluded) and one participant that experienced a brief spell of dizziness, participants did not report significant side effects during either study day.

\subsection{N-back}

The n-back (Gevins and Cutillo, 1993) is a test of executive functions which taps into working memory abilities and sustained attention. We used a well-validated neuroimaging version in which working memory load was parametrically modulated; this paradigm has previously shown to reliably increase frontal cortical and parietal activity (Owen et al., 2005) (i.e. task-positive areas) and is sensitive to manipulation of catecholamine function (Garrett et al., 2015; Winterer et al., 2006). Participants were instructed to detect target letters, which were presented for 1000 ms on an LCD screen. Participants viewed the screen using a periscopic mirror system. Targets constituted letters that were the same as the letter presented one, two, or three trials previously (i.e. 1-back, 2-back and 3-back). As a control condition, participants were asked to detect the letter ' $X$ ' (X-back). A condition consisted of eleven letters, separated by a fixation cross presented for 1000 ms. Every task condition was repeated three times in pseudo-random order. Per condition, three to four target letters were presented, amounting to a total number of eleven to twelve targets per condition. Participants responded to targets and distractors with right index finger and middle finger button presses, respectively. The total task duration was approximately $9 \mathrm{~min}$. Different versions of the task were used for each session; task versions were counterbalanced between participants (version 1-2 $n=10$; version 2-1 $n=9$; version 1 on ATX $n=11$; version 2 on ATX $n=8$ ). One performance dataset during an ATX session was lost due to a computer malfunction.

\subsection{Working memory capacity}

Working memory capacity was assessed using the auditory digit span test of the Wechsler Adult Intelligence Scale (WAIS-IV (Wechsler, 2008)). Participants were asked to repeat series of single-number digits that were read out loud in equally spaced one-second intervals by a trained experimenter. There were a total of eight difficulty levels, ranging from two- to nine-digit series, and each difficulty level consisted of two series. The task ended when participants failed two series of a given difficulty level. Working memory capacity was defined as the sum of correctly repeated series. This measure of working memory capacity has been shown to predict the effect of methylphenidate on working memory performance (Mehta et al., 2004) and correlates with working memory-related frontal cortical brain function (Mehta et al., 2000). Comparable measures of baseline working memory capacity furthermore predict DA synthesis capacity (Cools et al., 2008), demonstrating this measure's suitability as a surrogate marker of catecholamine function. Our measure of working memory capacity was obtained at the start of the first session.

\subsection{Image acquisition}

Images were acquired on a whole-body 3T MAGNETOM Prisma (Siemens; Erlangen, Germany). 270 functional T2*-weighted axial images aligned to the AC/PC line were acquired over a 9-minute period. Each volume consisted of $353 \mathrm{~mm}$-slices (.3 mm slice gap), acquired in interleaved fashion. Acquisition protocol details were: $\mathrm{TR}=2000 \mathrm{~ms}, \mathrm{TE}=30 \mathrm{~ms}$, flip angle $=77^{\circ}, \mathrm{FoV}=21.6 \mathrm{~cm}$, GRAPPA acceleration factor $=2$ and matrix size $=72 \times 72$. For coregistration purposes a T1-weighted high-resolution image (MPRAGE sequence) was acquired, consisting of $1921 \mathrm{~mm}$-sagittal slices acquired in interleaved fashion with $T R=2250 \mathrm{~ms}, T E=2.21 \mathrm{~ms}$, flip angle $=9^{\circ}, \mathrm{FoV}=25.6 \mathrm{~cm}$.

\subsection{Image preprocessing}

All image preprocessing steps and analyses were performed in Statistical Parametric Mapping 12 (SPM 12; http://www. fil.ion.ucl. ac.uk/spm/software/spm12/). Functional images were motion-corrected by registering the entire time series to the first volume using a rigid-body transformation. Participants were excluded if motion exceeded one voxel on more than three occasions. Not a single participant ever exceeded $2 \mathrm{~mm}$ or 1 . 5 degrees of motion. Next, images were co-registered to the anatomical image using a normalized mutual information algorithm, warped to MNI space using SPM's T1 template (causing images to be up-sampled to $2 \mathrm{~mm}^{3}$ voxels) and smoothed with a $6 \mathrm{~mm}$ FWHM kernel. For each session, a general linear model with four regressors of interest (X-, 1-, 2-, 3-back), their temporal derivatives and six motion regressors of no interest was constructed. The first two 
volumes of every condition were discarded to account for the delayed onset of the Blood Oxygen Level Dependent (BOLD) response. To account for signal drift, images were high-pass filtered $(128 \mathrm{~s})$ and serial correlations were accounted for using an AR (1) model. Anatomical images were segmented using SPM 12's segmentation algorithm (default settings). The resulting grey matter maps were inspected for fit and an average grey matter image of the entire sample was constructed, which was later used to mask out all but grey matter in group-level analyses.

\subsection{FMRI contrasts and functional connectivity analyses}

Whole-brain contrast images were generated at the first level to reveal regions where activity increased with cognitive demands (i.e. task-positive areas), compared to a control condition (Xback). Specifically, we focused on moderate (2-back) and high (3-back) working memory load blocks of the n-back task, as demands placed on PFC-mediated networks as well as the need for improvement are greatest during these conditions. The resulting contrast images (2-back/3-back $>$ X-back) were entered into a second level random effects analysis using a one-sample $t$-test with a cluster-forming threshold of $p<.001$, 20 voxel minimal cluster size and a FWE-corrected cluster threshold of $p<.05$.

Next, we investigated ATX's ability to strengthen FC between task-positive regions of the PFC network. We settled on two taskpositive PFC candidate seed regions which were used to investigate FC increases following ATX; we selected the right dIPFC and right anterior insula, based on abundant meta-analytical evidence demonstrating consistent involvement of these areas in tasks that assess working memory (Owen et al., 2005), salience detection (Cai et al., 2014) and, more generally, executive functions (Niendam et al., 2012).

Whole-brain FC maps for PLC and ATX sessions were produced using the general psychophysiological toolbox (v13.1) developed by McLaren et al. (McLaren et al., 2012). Conform previous work (Ye et al., 2015), we extracted time-series from a $6 \mathrm{~mm}$ sphere surrounding the peak voxel. For these purposes, we used the peak voxel coordinates identified from our PLC data $(n=19)$, comparing 3-back versus X-back. Importantly, however, the exact location of the peak voxel within the dIPFC (MNI: $x=44$ $y=38 \quad z=30$ ) and anterior insula (MNI: $x=30 \quad y=26 \quad z=0$ ) was always within two voxels of the peak voxel identified in metaanalyses (Cai et al., 2014; Niendam et al., 2012; Owen et al., 2005). Moreover, when we repeated the analyses with the coordinates identified in these meta-analyses, instead of our own data, we were able to reproduce the same FC maps, suggesting that our contrasts were unbiased.

A general linear model was created using the extracted time series, the psychological regressor (3-back/2-back=1, $X$-back $=-1$ ), the psychophysiological interaction and six motion regressors of no interest. The resulting maps for each session were conservatively threshold at $p<.001$ with a minimal cluster size of 20 voxels and FWE-corrected $p<.05$ at the cluster level. Grey matter was inclusively masked using the average grey matter image of our entire sample.

Group-level drug-induced effects on FC were investigated using a paired-samples $t$-test. ATX-induced increases in FC - using right insula and dIPFC as seed regions - were identified by subtracting $\mathrm{FC}_{\mathrm{PLC}}$ from $\mathrm{FC}_{\mathrm{ATX}}$ maps (i.e. $\mathrm{FC}_{\mathrm{ATX}}>\mathrm{FC}_{\mathrm{PLC}}$ ).

Frontal cortical regions that showed increased FC with dIPFC and insula were extracted using MarsBar (Brett et al., June 2-6, 2002) (v.44) for correlation analyses. Conform previous work, raw average values were extracted from these regions using a $6 \mathrm{~mm}$ sphere surrounding the peak voxel and converted to $Z$ scores (Rieckmann et al., 2012).

\subsection{Performance data}

All performance data were analyzed in SPSS (v23; IBM Corp, Arlington, NY).

We report accuracy (proportion correct answers) and reaction time variability (standard deviation of reaction time) for every condition of the n-back task. The effect of task difficulty on accuracy and reaction time stability was investigated using a repeated measures general linear model. Greenhouse-Geisser sphericity-corrected values were reported when assumptions were violated. The presence of a session-by-difficulty interaction was assessed using a $4 \times 2$ two-way repeated measures general linear model. Correlations between ATX-induced changes in FC and performance parameters sensitive to catecholamine function and working memory capacity were also investigated. For correlation analyses between ATX-induced changes in FC and working memory capacity, one influential case was detected with a studentized residual 2 times greater than the critical cutoff, which was excluded for this analysis. A threshold of $p<.025$ analyses was used for correlation analyses ( $p /$ seed regions used for FC analyses).

\section{Results}

\subsection{Behavioural performance}

The average digit span was $9.53(S D=2.14)$. With respect to n-back performance, there was a small but significant order effect on accuracy, where participants overall made fewer errors on session $2(M=.97, S D=.02)$, compared to session 1 $(M=.96, S D=.02)(t(17)=-2.37, p=.03)$. We therefore corrected for order effects in subsequent analyses, which did not affect our results (see below). On PLC $(F(2.22,40)$ $=25.13, p<.001)$ and $\operatorname{ATX}(F(3,39)=17.25, p<.001)$ there was an overall effect of task difficulty on accuracy, where accuracy decreased with increasing task demands. Bonferroni-corrected pairwise comparison revealed that 2back and 3-back accuracy was lower than X-back accuracy on PLC and ATX (Figure 1A). There was no session-bydifficulty interaction when correcting for order effects ( $F$ $(3,48)=1.02, p=.38)$.

Order effects for reaction time variability were not apparent $(t(17)=-.273, p=.79)$. Reaction time variability increased with task difficulty on PLC $(F(3,54)=31.22$, $p<.001)$ and ATX $(F(2.04,34.65)=28.22, p<.001)$, and there was no session-by-difficulty interaction $(F(3,51)$ $=.17, p=.92)$. On PLC and ATX, reaction time variability significantly increased on 1-back, 2-back and 3-back, compared to X-back (Figure 1B).

\subsection{Increased task-related activity in fronto- parietal regions on PLC and ATX during moderate and high working memory load}

As previously has been shown (Niendam et al., 2012; Owen et al., 2005), activity increases in response to moderate and high working memory demands were observed in frontoparietal regions, including dIPFC, anterior insula and parietal lobules (2-back/3-back > X-back; Figure 2A, B, D and E; for a list of all regions, please see Supplemental table 1A/B and $2 \mathrm{~A} / \mathrm{B})$. 

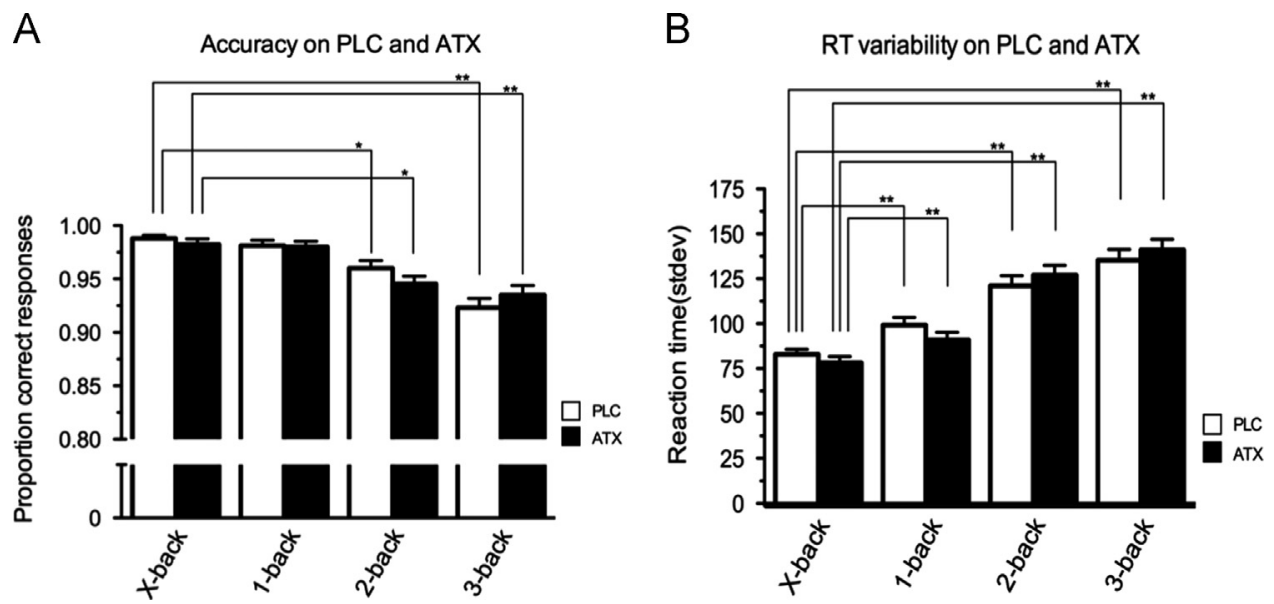

Figure 1 Accuracy (proportion correct; $1 \mathrm{~A}$ ) and reaction time variability (SD(reaction time); $1 \mathrm{~B}$ ) for every condition of the $\mathrm{n}$-back on PLC and ATX. On both occasions, there was a significant overall effect of task difficulty on accuracy and reaction time variability. ${ }^{* *}=p<.001 ;{ }^{*}=p<.05$.

A
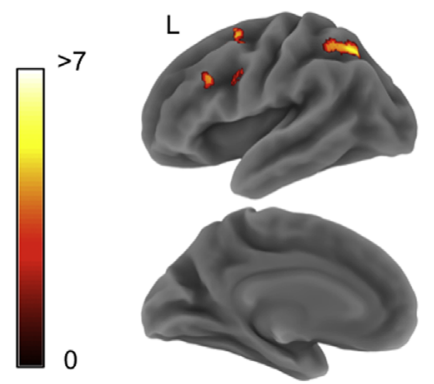

PLC 2-back $>X$-back

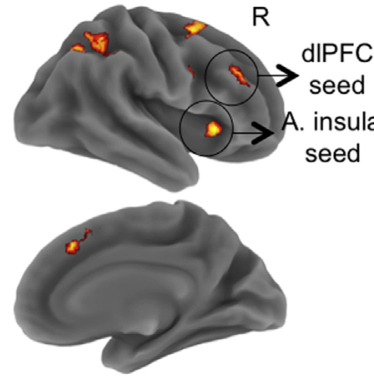

B
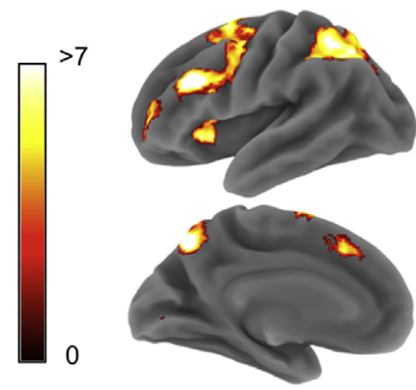

ATX 2-back>X-back

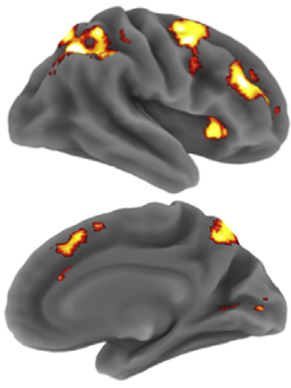

C
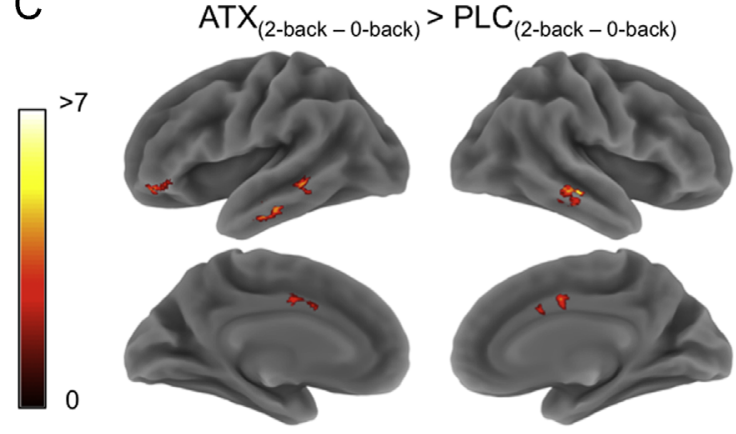

D

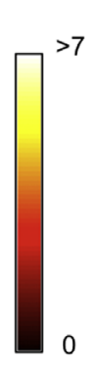

E

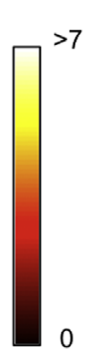

$\mathrm{F}$

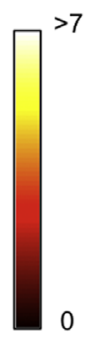

PLC 3-back>X-back
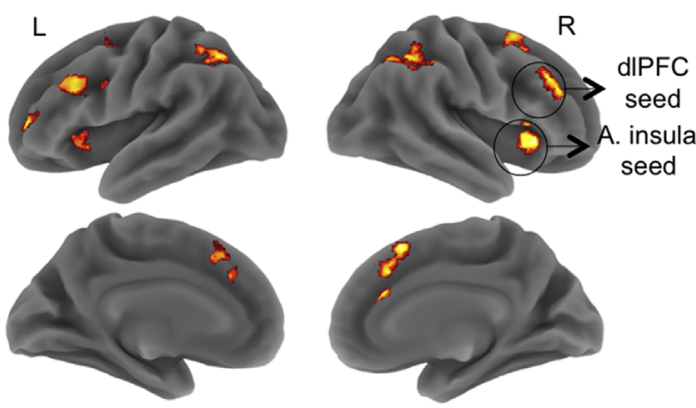

ATX 3-back>X-back
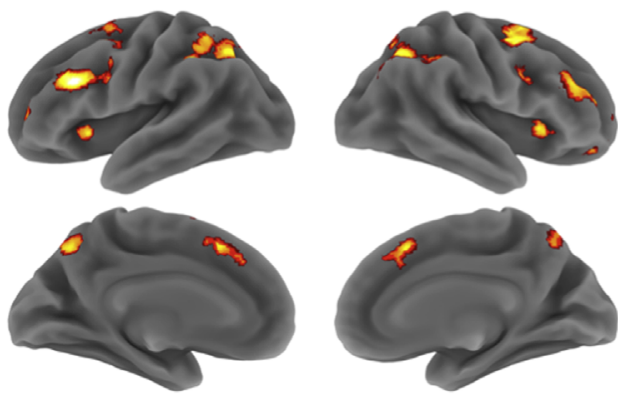

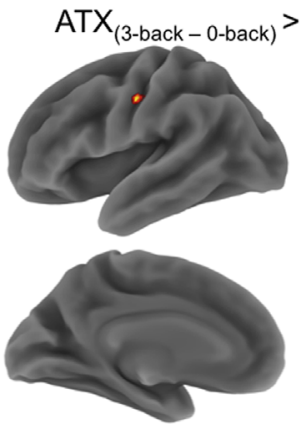

$\mathrm{PLC}_{(3-\text { back-0-back) }}$

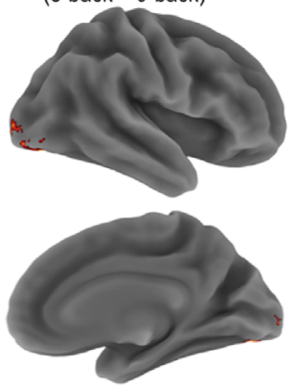

Figure 2 Task-induced activity increases on PLC and ATX for moderate (2A, B) and high (2D, E) working memory load. Greater activity increases on ATX versus PLC for moderate and high working memory load are shown in Figure $2 \mathrm{C}$ and $\mathrm{F}$ respectively. 
Table 1 Overview of regions showing significant activity increases on ATX versus PLC during moderate (1A) and high (1B) working memory load.

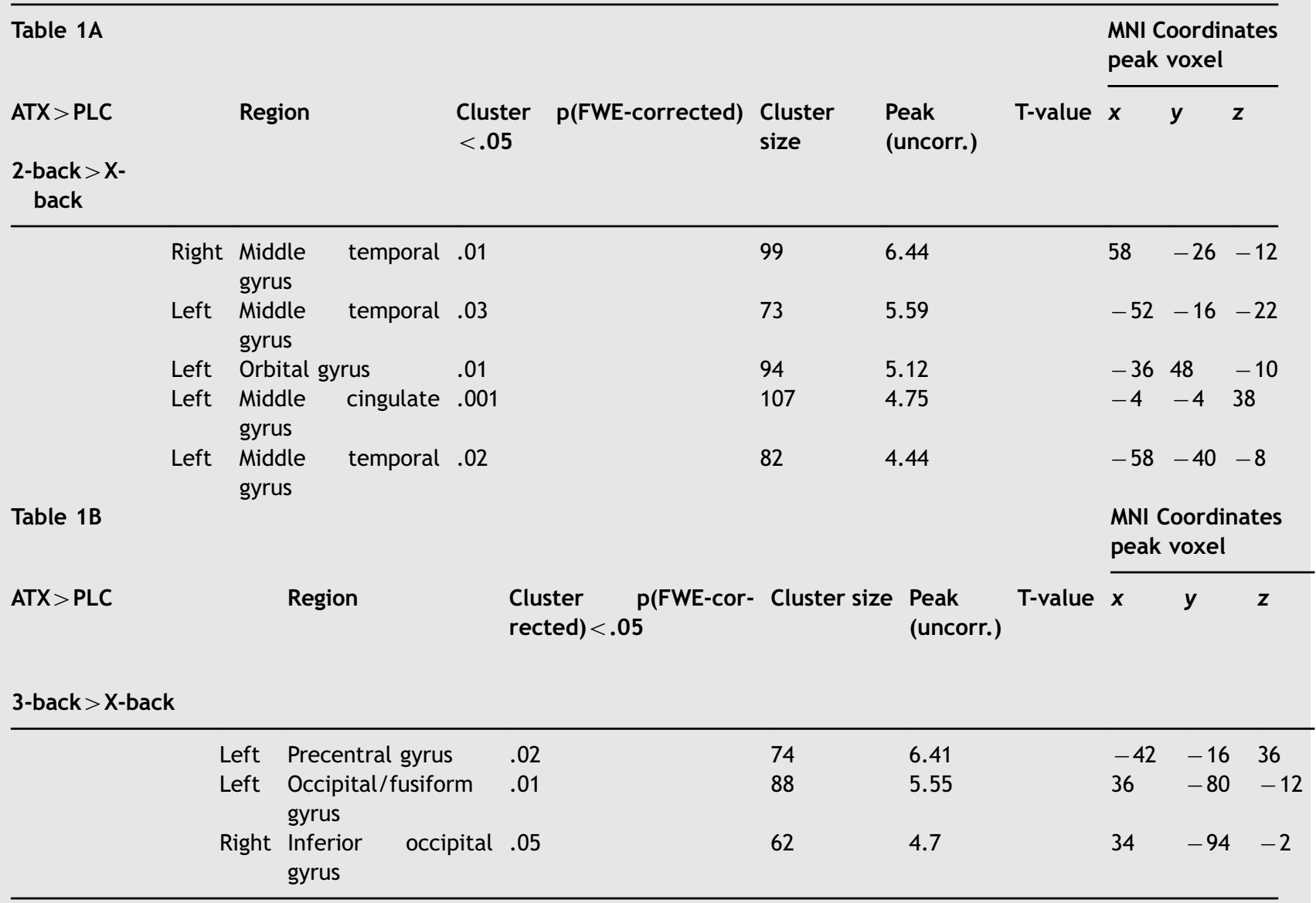

\subsection{Greater activity increases on ATX versus PLC during moderate and high working memory load}

Compared to PLC, ATX increased activity in temporal, middle cingulate and frontal orbital areas during conditions of moderate working memory load (2-back $>$ X-back) (Figure 2C; Table 1A). ATX-induced activity increases relative to PLC were greater in precentral gyrus and occipital cortex during the high working memory load condition (3back $>$ X-back; Figure 2F; Table 1B). No regions were identified where ATX decreased activity relative to PLC.

\subsection{ATX increases FC within a fronto-parietal task-positive network during high working memory} load

ATX did not increase FC between seed regions (right dIPFC and anterior insula) and other brain regions during the 2back relative to $X$-back condition. Moreover, right dIPFC FC was not modulated by ATX during 3-back relative to X-back. ATX did, however, strongly increase FC between right anterior insula and a fronto-parietal network consisting of precentral gyrus, left dIPFC, angular gyrus and, additionally, precuneus during 3-back relative to $\mathrm{X}$-back condition $\left(\mathrm{FC}_{\mathrm{ATX}}\right.$ - FC PLC; Figure 3C; Table 2), FC maps on PLC and ATX separately further verified this observation: on PLC, FC between anterior insula and other regions increased in response to increasing task demands, but this increase was greater on ATX (Figure $3 \mathrm{~A}$ and $\mathrm{B}$ ).

\subsection{ATX-induced increases in frontal cortical FC during high working memory load correlate with reaction time variability and are predicted by working memory capacity}

In order to understand the functional relevance of these findings, we investigated the association between ATXinduced changes in FC and task performance. Specifically, we looked at drug-induced changes in reaction time variability during the 3-back condition. Reaction time variability is associated with signal-to-noise ratio in PFC-mediated networks (Winterer et al., 2006), which is dependent on catecholamine function, especially frontal cortical DA, as demonstrated by pharmacological (Nandam et al., 2011), genetic (Saville et al., 2014; Winterer et al., 2006), and positron emission tomography (Aalto et al., 2005) studies. ATX-induced changes in 3-back reaction time variability were approximately normally distributed (skewness $=-.35$, kurtosis $=.26)$. 
A

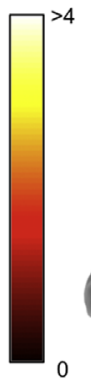

FC: PLC 3-back>X-back

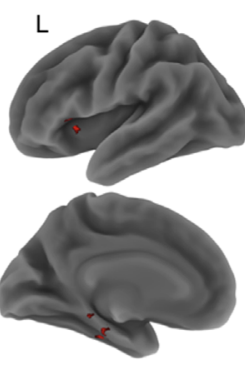

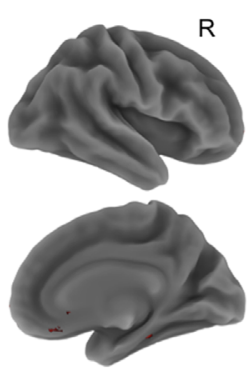

B

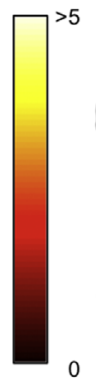

FC: ATX 3-back>X-back

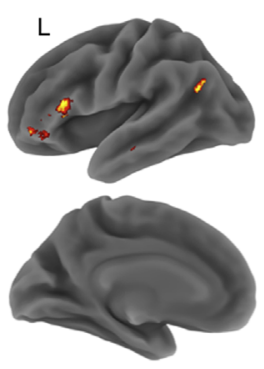

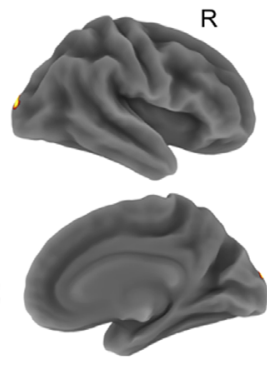

C

$\prod_{0}^{>7}$

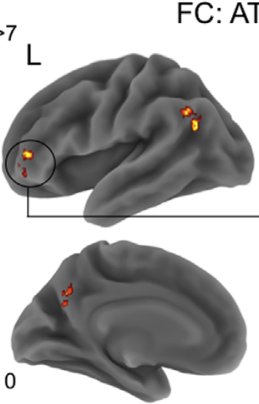

FC: $A T X>P L C$
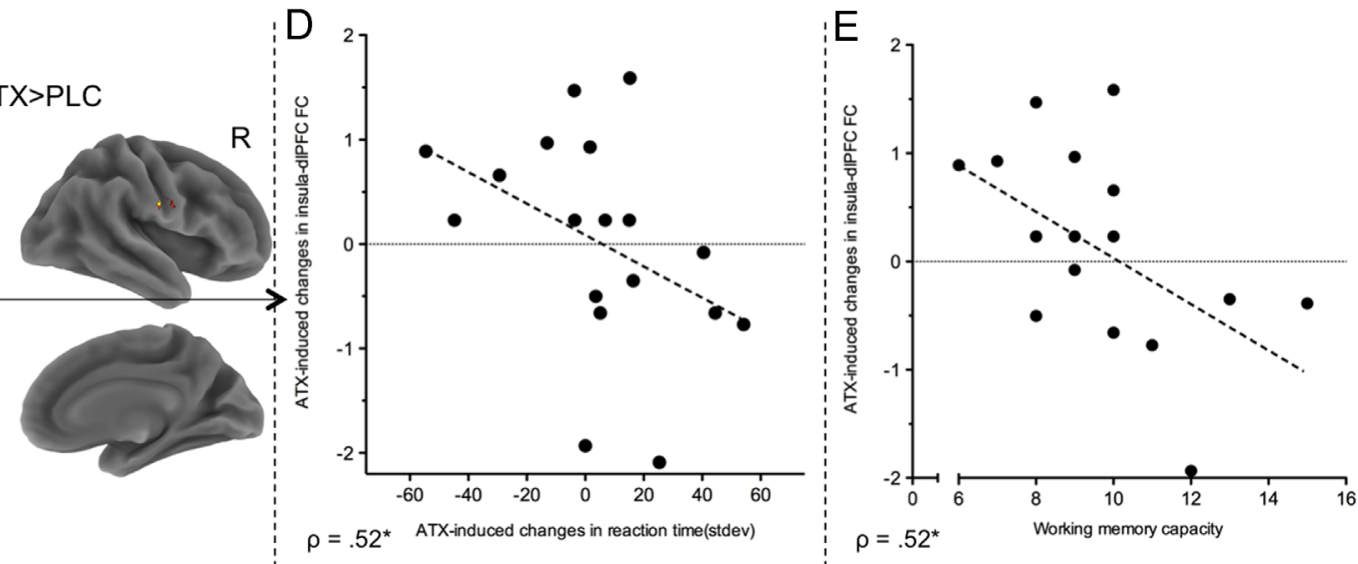

Figure $33 \mathrm{~A}$ Whole-brain FC map of the right insula on PLC. $\underline{3 B}$ Whole-brain FC of the right insula on ATX. 3A and 3B are thresholded for visualisation purposes. $3 C$ ATX-induced increases in FC between right insula and frontal cortical, parietal and occipital regions (FWE-corrected threshold of $p<.05$ ). 3D ATX-induced changes in insula-dIPFC FC negatively correlated with ATX-induced changes in 3-back reaction time variability. 3 E Working memory capacity predicts ATX-induced increases in insula-dIPFC FC.

Table 2 ATX increased FC between insula and frontal cortical, parietal and occipital regions during high working memory load. Regions in bold were used for correlation analyses.

Table 2

MNI Coordinates

peak voxel

\begin{tabular}{|c|c|c|c|c|c|c|c|c|}
\hline \multirow{2}{*}{$\begin{array}{l}F C_{A T X}-F C_{P L C} \\
\text { 3-back }>X- \\
\text { back }\end{array}$} & \multicolumn{2}{|r|}{ Region } & \multirow[t]{2}{*}{$\begin{array}{l}\text { Cluster } \quad \mathrm{p} \text { (FWE-cor- } \\
\text { rected })<.05\end{array}$} & \multirow[t]{2}{*}{$\begin{array}{l}\text { Cluster } \\
\text { size }\end{array}$} & \multirow[t]{2}{*}{$\begin{array}{l}\text { Peak } \\
\text { (uncorr.) }\end{array}$} & \multirow[t]{2}{*}{$x$} & \multirow[t]{2}{*}{$y$} & \multirow[t]{2}{*}{$z$} \\
\hline & & $\begin{array}{l}\text { Seed region: right } \\
\text { anterior insula }\end{array}$ & & & & & & \\
\hline & Left & Precuneus & .022 & 103 & 5.6 & -2 & -60 & 34 \\
\hline & Right & Precentral gyrus & .046 & 87 & 5.36 & 64 & -2 & 20 \\
\hline & Left & Inferior frontal gyrus & .046 & 87 & 4.73 & -40 & 42 & 4 \\
\hline & Left & Angular gyrus & .012 & 118 & 4.68 & -38 & -60 & 26 \\
\hline
\end{tabular}

ATX-induced increases in insula-dIPFC FC correlated negatively with ATX-induced changes in reaction time variability on 3-back, with greater ATX-induced increases in insula-dIPFC FC associated with decreased reaction time variability (i.e. increased stability) $(\rho=-.54 ; p=.02 ;$ Figure 3D). These results suggest that ATX-induced insula-dIPFC FC increases were associated with more consistent performance.

Finally, we investigated the association between ATXinduced changes in FC and working memory capacity. In line with our hypothesis, ATX-induced increases in insula-dIPFC FC correlated negatively with working memory capacity $(\rho=-.54 ; p=.02 ;$ Figure $3 \mathrm{E})$; insula-dlPFC FC increased more in individuals with lower WM capacity, compared to individuals with higher working memory capacity. Working memory capacity and ATX-induced changes in 3-back reaction time variability were not correlated $(\rho=-.39, p=.11)$.

\section{Discussion}

We set out to test the effect of NA transporter blockade on FC within PFC-mediated networks relevant to executive 
functions. Here, we offer novel evidence that NA transporter blockade strengthens FC between anterior insula and other fronto-parietal regions during conditions of high, but not moderate, working memory load. The extent to which ATX modulated insula-dIPFC FC was related to task performance and was predicted by a measure of working memory capacity. Below, we speculate on the implication of these findings.

Increased activity in bilateral dIPFC, especially IFG, insula and posterior parietal cortex in our sample during working memory performance accord well with metaanalytical studies of the n-back task (Owen et al., 2005) and, more generally, experimental tasks that tap into a diverse set of executive functions (Niendam et al., 2012). Moreover, the neurophysiological signature of high working memory load can be consistently observed in regions such as the dIPFC, posterior parietal cortex and anterior insula (Raabe et al., 2013; Van Snellenberg et al., 2015). All in all, these findings suggest that our paradigm activated wellknown regions of a task-positive network underlying working memory and attention.

Regardless of working memory load, the location of ATXinduced activity increases, relative to PLC, are also in line with previous work. Specifically, ATX has been shown to increase superior temporal gyrus activity during an n-back task (Cubillo et al., 2014) and increase superior temporal and precentral gyrus activity during a response inhibition task (Nandam et al., 2014). In ADHD, prolonged ATX treatment was associated with increased fusiform face area and middle cingulate gyrus activity during a response-conflict task (Bush et al., 2013). Given that all these tasks tap into different aspects of executive functions, common activity changes across studies could reflect ATX's general mechanism of action, rather than a task-specific effect.

We observed that ATX accentuated FC between anterior insula and precentral gyrus, precuneus, dIPFC and angular gyrus during high working memory load. The anterior insula has been ascribed the role of salience detection (Cai et al., 2014), demonstrated by activity increases to stimuli that stand out from the context that they are presented in (Menon and Uddin, 2010; Sridharan et al., 2008). Importantly, regions that the anterior insula increased FC with on ATX were fundamental for task performance, with the dIPFC underlying working memory performance (Goldman-Rakic, 1995), the posterior parietal cortex involved in attentional processes (Nickel and Seitz, 2005) and precentral gyrus important for motor responses. Increased FC with the precuneus was somewhat surprising, as this region is often implicated in the default mode network (McKiernan et al., 2003). However, increased precuneus activity has previously been reported during paradigms that strain working memory limits (Raabe et al., 2013; Van Snellenberg et al., 2015) and could reflect recruitment of outside-ofnetwork regions to help maintain performance.

The novelty of our findings is that increased levels of extracellular DA and NA, the result of NA transporter blockade, lead to a global reallocation of processing resources that favours working memory-related networks. They provide novel insights into the effects of DA and NA on functional networks that subserve working memory and suggest that, similar to DA agonists (Bloemendaal et al., 2015; Cole et al., 2013), NA transporter inhibitors modulate these networks. The fact that FC increases were only observed during high working memory load may be related to sub-optimal performance in this condition. Indeed, accuracy and reaction time stability were poorest in the 3-back condition (significantly poorer than 2-back). In light of relatively intact performance during the 2-back condition, 3-back may have strained working memory limits, similar to previous studies reporting drug effects on working memory performance (Grundey et al., 2015) and associated neural activity (Gelao et al., 2014; Loughead et al., 2009) specifically in the 3-back condition.

The observation that ATX-induced changes in insula-dIPFC FC correlated with changes in reaction time variability adds to an existing body of literature showing that performance stability is closely linked to catecholamine function. Previously, increased ventrolateral DA release during a verbal working memory task was found to correlate with decreased reaction time stability (Aalto et al., 2005). Moreover, methylphenidate, a non-selective DA and NA reuptake inhibitor, and clonidine, an $\alpha 2$ adrenergic receptor agonist that attenuates NA function, decreased and increased reaction time stability during a response inhibition task respectively (Logemann et al., 2013; Nandam et al., 2011). Such effects were not observed for atomoxetine (Nandam et al., 2011). This latter observation is consistent with our own data, where no overall changes in reaction variability were observed in response to ATX. In older individuals, methylphenidate-induced increases in performance stability are co-observed with decreased signal variability in among others dIPFC activity during an n-back task (Garrett et al., 2015). Similarly, more efficient processing in dIPFC during an n-back task has been shown for carriers of the COMT Val-allele, compared to their Met counterparts (Winterer et al., 2006). These results underscore that the beneficial effects of ATX on brain function and corresponding behaviour observed in some of our participants are likely to involve increases in DA and NA function. Our data add to the notion that agents with a predominant NAergic mechanism of action can improve aspects of executive functions in some, but not all, individuals. At the conceptual level, increased ATX-induced insula-dIPFC FC could reflect optimization of signal-to-noise ratio in neural networks relevant for task performance, either via increased signal processing, decreased noise interference or both (Gamo et al., 2010). Future studies should focus on further elucidating individual contributions of the DA and NA system to working memory networks.

Interestingly, the extent to which ATX modulated insuladIPFC FC was predicted by baseline working memory capacity, with individuals with a lower working memory span showing greater increases in FC in response to ATX. Similar observations have been reported for D2 agonist bromocriptine (Kimberg et al., 1997) and methylphenidate (Mehta et al., 2004), where cognitive performance after drug administration improved the most in those with low working memory span. At the neurochemical level, these effects may be related to low baseline DA synthesis capacity (Cools et al., 2008) and, at the functional level, to inefficient information processing (Mattay et al., 2003). In light of the observed association between insula-dIPFC FC and reaction time variability, we interpret the effect of ATX on insula-dIPFC FC in individuals with a low working memory capacity as beneficial to performance.

While some participants improved in task performance and frontal cortical FC on ATX, not all did; especially those 
with high working memory capacity. These findings accord well with the notion that the relation between catecholamine function and cognitive performance can be described as an inverted-u curve, where performance is suboptimal at either extremity of this curve (Arnsten, 2011). Increased cortical extracellular DA and NA levels may have pushed individuals with a low working memory capacity to their optimum, but could have resulted in a performance decrement in those with a higher working memory capacity. Our measure of working memory capacity may have served as a proxy of baseline catecholamine function (Cools et al., 2008); similar results have been reported for other proxies of catecholamine function such as amphetamine-induced increases in cortical efficiency during an n-back task in carriers of the high-activity Val-allele (Mattay et al., 2003) and improved reversal learning following bromocriptine in individuals with low DA synthesis capacity (Cools et al., 2009). To our knowledge, the observation that a NA transporter inhibitor exerts effects on working memory performance and associated FC that could resemble an inverted-U curve is a novel one.

Although the presented results support the conclusion that ATX accentuates fronto-parietal network activity during high working memory load, non-neural effects may, partly, account for this observation. Specifically, ATX may have produced hemodynamic changes via neurovascular coupling; PFC and parietal perfusion changes have been shown in response to ATX (Marquand et al., 2012) and methylphenidate (O'Gorman et al., 2008). On the other hand, cerebral perfusion in Parkinson's disease is unaffected by ATX (Rae et al., 2016) (demonstrated by perfusion and dynamic causal modelling analyses), and intravenous administration of noradrenaline does not affect cerebral blood flow (Moppett et al., 2008). Thus, while there may be some effects of ATX on the neurovasculature, future investigations into the relation between ATX-induced changes in cerebral perfusion, task-related activity and FC are clearly warranted.

All in all, the current results yield new insights into the effect of ATX on functional brain networks underlying working memory and attention. Moreover, they demonstrate that FC is a useful measure to assess drug effects, which meaningfully relates to performance and is predicted by measures of working memory capacity. Such measures could lead to a better understanding and prediction of DAergic and NAergic drug effects in clinical disorders with a heterogeneous treatment response such as ADHD.

\subsection{Limitations}

Due to the use of a block design, we were unable to investigate which specific executive functions were affected by ATX. The correlation between FC and reaction time variability and increased FC between insula and Brodmann area 46 (left IFG) suggest that ATX may have facilitated response selection (Rowe and Passingham, 2001). On the other hand, the association between auditory digit span and insula-left IFG FC could point to an effect on maintenance. Here, the use of an event-related design that separates encoding-, maintenance- and response-related events, as utilized previously (Marquand et al., 2011; Rowe et al., 2000), could have been valuable.

Moreover, we used auditory digit span as a proxy of catecholamine function. While a similar measure of working memory capacity correlates with DA synthesis capacity (Cools et al., 2008), it should be noted that no such associations have been reported for our measure of auditory digit span. Moreover, it also not entirely clear how working memory capacity relates to NA function. Nevertheless, previous work has shown that auditory digit span predicts the effect of a non-selective catecholamine agonist on cognitive performance (Mehta et al., 2004), hinting at the idea that working memory capacity may be related to both baseline NA and DA function. This notion is further supported by the observation that selective NAergic agents modulate working memory performance (Arnsten, 2011).

A final limitation to take into account is the sample size. In order to limit our chances of a false positive we used a conservative statistical threshold in our neuroimaging, especially FC, analyses. Nevertheless, future replications with a larger sample size will be important to ascertain the reliability of the reported findings.

\section{Conclusions}

We investigated how NA transporter blockade modulates FC in frontal cortical networks underlying working memory performance. Our results indicate that ATX-induced increased levels of DA and NA modulated connectivity between fronto-parietal hubs typically involved in a variety of executive functions. Increased ATX-induced insula-dIPFC FC, two regions essential for task performance, was negatively correlated with changes in reaction time variability and most pronounced in individuals with low working capacity. These findings demonstrate that agents with a predominant NAergic mechanism of action can strengthen working memory networks, providing a novel angle of evidence for NA transporter inhibitors in the treatment of cognitive disorders. Large inter-individual differences in drug response could hint at an inverted-u relation between frontal cortical network integrity and catecholamine levels, which could be relevant in improving prediction of treatment effects. Direct comparison of selective DAergic and NAergic enhancement could provide a fine-grained understanding of the individual contributions of these catacholamines to working memory networks.

\section{Role of the funding source}

DH's research is funded by a Kootstra post-doctoral fellowship (10-2014) and a Brains Unlimited pioneer grant (S.2015.1.02). TvAs research is funded by a ZonMW VIDI grant (91712394). These funding sources had no involvement in the study.

\section{Contributors}

$\mathrm{DH}$ designed the study and wrote the protocol. $\mathrm{DH}$, JO and $\mathrm{MC}$ collected the data. DH and TvA funded the study and wrote the manuscript. All authors contributed to and have approved the final manuscript. 


\section{Conflict of interest}

The authors declare no competing financial interests.

\section{Acknowledgements}

We thank Wendy Beuken for her involvement in the administrative aspects of this study.

\section{Appendix A. Supporting information}

Supplementary data associated with this article can be found in the online version at http://dx.doi.org/10.1016/ j.euroneuro.2017.02.004.

\section{References}

Aalto, S., Bruck, A., Laine, M., Nagren, K., Rinne, J.O., 2005. Frontal and temporal dopamine release during working memory and attention tasks in healthy humans: a positron emission tomography study using the high-affinity dopamine D2 receptor ligand [11C]FLB 457. J. Neurosci. 25 (10), 2471-2477.

Arnsten, A.F., 2011. Catecholamine influences on dorsolateral prefrontal cortical networks. Biol. Psychiatry 69 (12), e89-e99.

Bloemendaal, M., van Schouwenburg, M.R., Miyakawa, A., Aarts, E., D'Esposito, M., Cools, R., 2015. Dopaminergic modulation of distracter-resistance and prefrontal delay period signal. Psychopharmacology 232 (6), 1061-1070.

Borchert, R.J., Rittman, T., Passamonti, L., Ye, Z., Sami, S., Jones, S.P., et al., 2016. Atomoxetine enhances connectivity of prefrontal networks in Parkinson's disease. Neuropsychopharmacol.: Off. Publ. Am. Coll. Neuropsychopharmacol. 41 (8), 2188.

Brett, M., Anton, J., Valabregue, R., Poline, J. 2002. (June 2-6). Region of interest analysis using an SPM toolbox Presented at In: Proceedings of the 8th International Conference on Functional Mapping of the Human Brain. Sendai, Japan: Sendai, Japan.

Bush, G., Holmes, J., Shin, L.M., Surman, C., Makris, N., Mick, E., et al., 2013. Atomoxetine increases fronto-parietal functional MRI activation in attention-deficit/hyperactivity disorder: a pilot study. Psychiatry Res. 211 (1), 88-91.

Bymaster, F.P., Katner, J.S., Nelson, D.L., Hemrick-Luecke, S.K., Threlkeld, P.G., Heiligenstein, J.H., et al., 2002. Atomoxetine increases extracellular levels of norepinephrine and dopamine in prefrontal cortex of rat: a potential mechanism for efficacy in attention deficit/hyperactivity disorder. Neuropsychopharmacol.: Off. Publ. Am. Coll. Neuropsychopharmacol. 27 (5), 699-711.

Cai, W., Ryali, S., Chen, T., Li, C.S., Menon, V., 2014. Dissociable roles of right inferior frontal cortex and anterior insula in inhibitory control: evidence from intrinsic and task-related functional parcellation, connectivity, and response profile analyses across multiple datasets. J. Neurosci. 34 (44), 14652-14667.

Cole, D.M., Oei, N.Y., Soeter, R.P., Both, S., van Gerven, J.M., Rombouts, S.A., et al., 2013. Dopamine-dependent architecture of cortico-subcortical network connectivity. Cereb. Cortex 23 (7), 1509-1516.

Cools, R., Frank, M.J., Gibbs, S.E., Miyakawa, A., Jagust, W., D'Esposito, M., 2009. Striatal dopamine predicts outcomespecific reversal learning and its sensitivity to dopaminergic drug administration. J. Neurosci. 29 (5), 1538-1543.

Cools, R., Gibbs, S.E., Miyakawa, A., Jagust, W., D'Esposito, M., 2008. Working memory capacity predicts dopamine synthesis capacity in the human striatum. J. Neurosci. 28 (5), 1208-1212.
Cubillo, A., Smith, A.B., Barrett, N., Giampietro, V., Brammer, M., Simmons, A., et al., 2014. Drug-specific laterality effects on frontal lobe activation of atomoxetine and methylphenidate in attention deficit hyperactivity disorder boys during working memory. Psychol. Med. 44 (3), 633-646.

Ding, Y.S., Naganawa, M., Gallezot, J.D., Nabulsi, N., Lin, S.F., Ropchan, J., et al., 2014. Clinical doses of atomoxetine significantly occupy both norepinephrine and serotonin transports: implications on treatment of depression and ADHD. Neurolmage 86, 164-171.

Dolphin, A., Jenner, P., Marsden, C.D., 1976. Noradrenaline synthesis from L-DOPA in rodents and its relationship to motor activity. Pharmacol., Biochem., Behav. 5 (4), 431-439.

Everett, G.M., Borcherding, J.W., 1970. L-DOPA: effect on concentrations of dopamine, norepinephrine, and serotonin in brains of mice. Science 168 (3933), 847-850.

Gamo, N.J., Wang, M., Arnsten, A.F., 2010. Methylphenidate and atomoxetine enhance prefrontal function through alpha2adrenergic and dopamine D1 receptors. J. Am. Acad. Child Adolesc. Psychiatry 49 (10), 1011-1023.

Garrett, D.D., Nagel, I.E., Preuschhof, C., Burzynska, A.Z., Marchner, J., Wiegert, S., et al., 2015. Amphetamine modulates brain signal variability and working memory in younger and older adults. Proc. Natl. Acad. Sci. U. S. A. 112 (24), 7593-7598.

Gelao, B., Fazio, L., Selvaggi, P., Di Giorgio, A., Taurisano, P., Quarto, T., et al., 2014. DRD2 genotype predicts prefrontal activity during working memory after stimulation of D2 receptors with bromocriptine. Psychopharmacology 231 (11), 2361-2370.

Gevins, A., Cutillo, B., 1993. Spatiotemporal dynamics of component processes in human working memory. Electroencephalogr. Clin. Neurophysiol. 87 (3), 128-143.

Gilbert, D.L., Ridel, K.R., Sallee, F.R., Zhang, J., Lipps, T.D., Wassermann, E.M., 2006. Comparison of the inhibitory and excitatory effects of ADHD medications methylphenidate and atomoxetine on motor cortex. Neuropsychopharmacol.: Off. Publ. Am. Coll. Neuropsychopharmacol. 31 (2), 442-449.

Glahn, D.C., Ragland, J.D., Abramoff, A., Barrett, J., Laird, A.R., Bearden, C.E., et al., 2005. Beyond hypofrontality: a quantitative meta-analysis of functional neuroimaging studies of working memory in schizophrenia. Hum. Brain Map. 25 (1), 60-69.

Goldman-Rakic, P.S., 1995. Cellular basis of working memory. Neuron 14 (3), 477-485.

Grundey, J., Amu, R., Ambrus, G.G., Batsikadze, G., Paulus, W., Nitsche, M.A., 2015. Double dissociation of working memory and attentional processes in smokers and non-smokers with and without nicotine. Psychopharmacology 232 (14), 2491-2501.

Hart, H., Radua, J., Nakao, T., Mataix-Cols, D., Rubia, K., 2013. Meta-analysis of functional magnetic resonance imaging studies of inhibition and attention in attention-deficit/hyperactivity disorder: exploring task-specific, stimulant medication, and age effects. JAMA Psychiatry 70 (2), 185-198.

Hester, R., Nandam, L.S., O'Connell, R.G., Wagner, J., Strudwick, M., Nathan, P.J., et al., 2012. Neurochemical enhancement of conscious error awareness. J. Neurosci. 32 (8), 2619-2627.

Kimberg, D.Y., D'Esposito, M., Farah, M.J., 1997. Effects of bromocriptine on human subjects depend on working memory capacity. Neuroreport 8 (16), 3581-3585.

Lissek, S., Glaubitz, B., Gunturkun, O., Tegenthoff, M., 2015. Noradrenergic stimulation modulates activation of extinctionrelated brain regions and enhances contextual extinction learning without affecting renewal. Front. Behav. Neurosci. 9, 34.

Logemann, H.N., Bocker, K.B., Deschamps, P.K., Kemner, C., Kenemans, J.L., 2013. The effect of noradrenergic attenuation by clonidine on inhibition in the stop signal task. Pharmacol., Biochem., Behav. 110, 104-111.

Loughead, J., Wileyto, E.P., Valdez, J.N., Sanborn, P., Tang, K., Strasser, A.A., et al., 2009. Effect of abstinence challenge on 
brain function and cognition in smokers differs by COMT genotype. Mol. Psychiatry 14 (8), 820-826.

Marquand, A.F., De Simoni, S., O'Daly, O.G., Williams, S.C., MouraoMiranda, J., Mehta, M.A., 2011. Pattern classification of working memory networks reveals differential effects of methylphenidate, atomoxetine, and placebo in healthy volunteers. Neuropsychopharmacol.: Off. Publ. Am. Coll. Neuropsychopharmacol. 36 (6), 1237-1247.

Marquand, A.F., O'Daly, O.G., De Simoni, S., Alsop, D.C., Maguire, R.P., Williams, S.C., et al., 2012. Dissociable effects of methylphenidate, atomoxetine and placebo on regional cerebral blood flow in healthy volunteers at rest: a multi-class pattern recognition approach. Neurolmage 60 (2), 1015-1024.

Mattay, V.S., Goldberg, T.E., Fera, F., Hariri, A.R., Tessitore, A., Egan, M.F., et al., 2003. Catechol O-methyltransferase val158met genotype and individual variation in the brain response to amphetamine. Proc. Natl. Acad. Sci. U. S. A. 100 (10), 6186-6191.

McKiernan, K.A., Kaufman, J.N., Kucera-Thompson, J., Binder, J. R., 2003. A parametric manipulation of factors affecting taskinduced deactivation in functional neuroimaging. J. Cogn. Neurosci. 15 (3), 394-408.

McLaren, D.G., Ries, M.L., Xu, G., Johnson, S.C., 2012. A generalized form of context-dependent psychophysiological interactions (gPPI): a comparison to standard approaches. Neurolmage 61 (4), 1277-1286.

Mehta, M.A., Goodyer, I.M., Sahakian, B.J., 2004. Methylphenidate improves working memory and set-shifting in $A D / H D$ : relationships to baseline memory capacity. J. Child Psychol. Psychiatry, Allied Discip. 45 (2), 293-305.

Mehta, M.A., Owen, A.M., Sahakian, B.J., Mavaddat, N., Pickard, J. D., Robbins, T.W., 2000. Methylphenidate enhances working memory by modulating discrete frontal and parietal lobe regions in the human brain. J. Neurosci. 20 (6), RC65.

Menon, V., Uddin, L.Q., 2010. Saliency, switching, attention and control: a network model of insula function. Brain Struct. Funct. 214 (5-6), 655-667.

Moppett, I.K., Sherman, R.W., Wild, M.J., Latter, J.A., Mahajan, R. P., 2008. Effects of norepinephrine and glyceryl trinitrate on cerebral haemodynamics: transcranial Doppler study in healthy volunteers. Br. J. Anaesth. 100 (2), 240-244.

Nandam, L.S., Hester, R., Bellgrove, M.A., 2014. Dissociable and common effects of methylphenidate, atomoxetine and citalopram on response inhibition neural networks. Neuropsychologia 56, 263-270.

Nandam, L.S., Hester, R., Wagner, J., Cummins, T.D., Garner, K., Dean, A.J., et al., 2011. Methylphenidate but not atomoxetine or citalopram modulates inhibitory control and response time variability. Biol. Psychiatry 69 (9), 902-904.

Nickel, J., Seitz, R.J., 2005. Functional clusters in the human parietal cortex as revealed by an observer-independent metaanalysis of functional activation studies. Anat. Embryol. 210 (56), 463-472.

Niendam, T.A., Laird, A.R., Ray, K.L., Dean, Y.M., Glahn, D.C., Carter, C.S., 2012. Meta-analytic evidence for a superordinate cognitive control network subserving diverse executive functions. Cogn., Affect. Behav. Neurosci. 12 (2), 241-268.

O'Gorman, R.L., Mehta, M.A., Asherson, P., Zelaya, F.O., Brookes, K. J., Toone, B.K., et al., 2008. Increased cerebral perfusion in adult attention deficit hyperactivity disorder is normalised by stimulant treatment: a non-invasive MRI pilot study. Neurolmage 42 (1), 36-41.

O'Reilly, J.X., Woolrich, M.W., Behrens, T.E., Smith, S.M., JohansenBerg, H., 2012. Tools of the trade: psychophysiological interactions and functional connectivity. Social. Cogn. Affect. Neurosci. 7 (5), 604-609.
Owen, A.M., McMillan, K.M., Laird, A.R., Bullmore, E., 2005. N-back working memory paradigm: a meta-analysis of normative functional neuroimaging studies. Hum. Brain Map. 25 (1), 46-59.

Power, J.D., Barnes, K.A., Snyder, A.Z., Schlaggar, B.L., Petersen, S.E., 2012. Spurious but systematic correlations in functional connectivity MRI networks arise from subject motion. NeuroImage 59 (3), 2142-2154.

Raabe, M., Fischer, V., Bernhardt, D., Greenlee, M.W., 2013. Neural correlates of spatial working memory load in a delayed matchto-sample saccade task. Neurolmage 71, 84-91.

Rae, C.L., Nombela, C., Rodriguez, P.V., Ye, Z., Hughes, L.E., Jones, P.S., et al., 2016. Atomoxetine restores the response inhibition network in Parkinson's disease. Brain 139 (Pt 8), 2235-2248.

Rieckmann, A., Karlsson, S., Fischer, H., Backman, L., 2012. Increased bilateral frontal connectivity during working memory in young adults under the influence of a dopamine D1 receptor antagonist. J. Neurosci. 32 (48), 17067-17072.

Rowe, J.B., Passingham, R.E., 2001. Working memory for location and time: activity in prefrontal area 46 relates to selection rather than maintenance in memory. Neurolmage 14 (1 Pt 1), 77-86.

Rowe, J.B., Toni, I., Josephs, O., Frackowiak, R.S., Passingham, R. E., 2000. The prefrontal cortex: response selection or maintenance within working memory? Science 288 (5471), 1656-1660.

Saville, C.W., Lancaster, T.M., Stefanou, M.E., Salunkhe, G., Lourmpa, I., Nadkarni, A., et al., 2014. COMT Val158Met genotype is associated with fluctuations in working memory performance: converging evidence from behavioural and singletrial P3b measures. Neurolmage 100, 489-497.

Sawaguchi, T., Goldman-Rakic, P.S., 1994. The role of D1-dopamine receptor in working memory: local injections of dopamine antagonists into the prefrontal cortex of rhesus monkeys performing an oculomotor delayed-response task. J. Neurophysiol. 71 (2), 515-528.

Seamans, J.K., Gorelova, N., Durstewitz, D., Yang, C.R., 2001. Bidirectional dopamine modulation of GABAergic inhibition in prefrontal cortical pyramidal neurons. J. Neurosci. 21 (10), 3628-3638.

Sridharan, D., Levitin, D.J., Menon, V., 2008. A critical role for the right fronto-insular cortex in switching between centralexecutive and default-mode networks. Proc. Natl. Acad. Sci. U. S. A. 105 (34), 12569-12574.

van den Brink, R.L., Pfeffer, T., Warren, C.M., Murphy, P.R., Tona, K.D., van der Wee, N.J., et al., 2016. Catecholaminergic neuromodulation shapes intrinsic MRI functional connectivity in the human brain. J. Neurosci. 36 (30), 7865-7876.

Van Snellenberg, J.X., Slifstein, M., Read, C., Weber, J., Thompson, J.L., Wager, T.D., et al., 2015. Dynamic shifts in brain network activation during supracapacity working memory task performance. Hum. Brain Map. 36 (4), 1245-1264.

Vijayraghavan, S., Wang, M., Birnbaum, S.G., Williams, G.V., Arnsten, A.F., 2007. Inverted-U dopamine D1 receptor actions on prefrontal neurons engaged in working memory. Nat. Neurosci. 10 (3), 376-384.

Wang, M., Ramos, B.P., Paspalas, C.D., Shu, Y., Simen, A., Duque, A., et al., 2007. Alpha2A-adrenoceptors strengthen working memory networks by inhibiting CAMP-HCN channel signaling in prefrontal cortex. Cell 129 (2), 397-410.

Wardle, M.C., Hart, A.B., Palmer, A.A., de Wit, H., 2013. Does COMT genotype influence the effects of $d$-amphetamine on executive functioning? Genes Brain Behav. 12 (1), 13-20.

Wechsler, D., 2008. Wechsler Adult Intelligence Scale Fourth Edition Pearson, San Antonio, TX, USA.

Winterer, G., Musso, F., Vucurevic, G., Stoeter, P., Konrad, A., Seker, B., et al., 2006. COMT genotype predicts BOLD signal and noise characteristics in prefrontal circuits. Neurolmage 32 (4), $1722-1732$ 
Witcher, J.W., Long, A., Smith, B., Sauer, J.M., Heilgenstein, J., Wilens, T., et al., 2003. Atomoxetine pharmacokinetics in children and adolescents with attention deficit hyperactivity disorder. J. Child Adolesc. Psychopharmacol. 13 (1), 53-63.

Ye, Z., Altena, E., Nombela, C., Housden, C.R., Maxwell, H., Rittman, T., et al., 2015. Improving response inhibition in
Parkinson's disease with atomoxetine. Biol. Psychiatry 77 (8), 740-748.

Zhang, R., Picchioni, M., Allen, P., Toulopoulou, T., 2016. Working memory in unaffected relatives of patients with schizophrenia: a meta-analysis of functional magnetic resonance imaging studies. Schizophr. Bull. 42 (4), 1068-1077. 